\title{
Bowdler spur also found in camptomelic dysplasia
}

\author{
Alan E. Oestreich ${ }^{1}$ \\ Received: 27 August 2015 / Accepted: 23 September 2015 /Published online: 6 October 2015 \\ (C) Springer-Verlag Berlin Heidelberg 2015
}

Sir,

In a previous article in this journal we referred to the now well-known Bowdler spur manifestation of hypophosphatasia [1]. These transverse smoothly marginated spurs of bone near the convex side of the midshaft of bent long bones are associated with a deep skin dimple visible on radiographs. The Bowdler spurs have been repeatedly seen in hypophosphatasia since first reported by Denby Bowdler at the 1970 meeting of the Gesellschaft für Pädiatrische Radiologie in Zürich (as quoted in [2]).

We have now encountered similar Bowdler spurs in a 20-year-old woman with camptomelic dysplasia, associated with the bowed bones, which are a defining feature of this dysplasia (Fig. 1). The broad protrusion of the tibia seen on radiographs of the same patient on the second day of life, opposite the cutaneous dimple (Fig. 1), was not initially perceived as the Bowdler spur that was evident later in life.

Because the reason for Bowdler spurs in hypophosphatasia is not known, the finding of a similar manifestation in camptomelic dysplasia implies that some unidentified disturbance of cartilage growth associated with certain bowed bones may be responsible.

Alan E. Oestreich

alan.oestreich@cchmc.org

1 Department of Radiology,

Cincinnati Children's Hospital Medical Center, Radiology 5031,

3333 Burnet Ave., Cincinnati, OH 45229-3039, USA
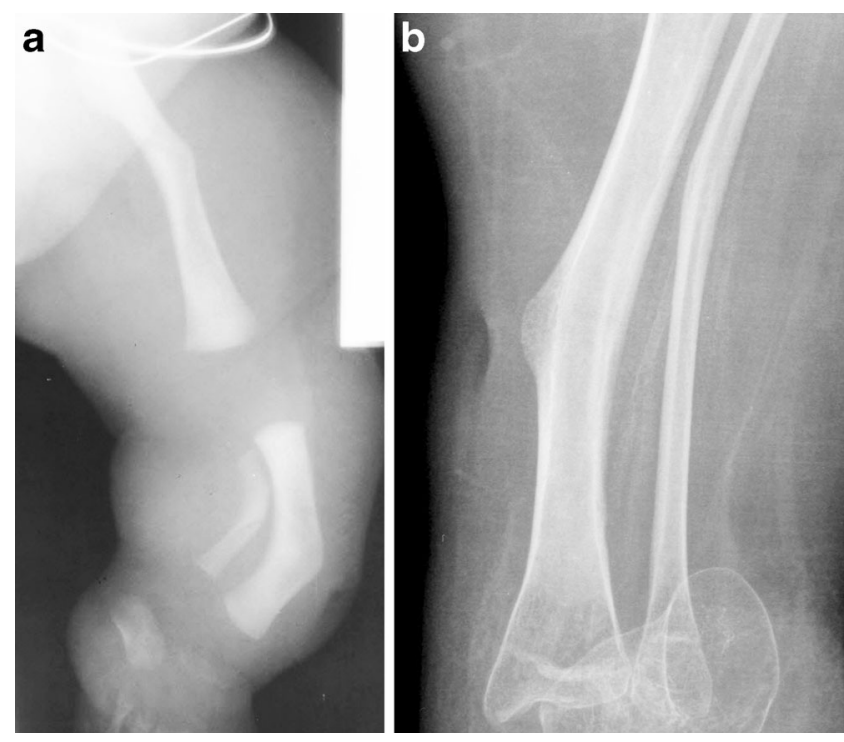

Fig. 1 Bowdler spur in an infant girl with camptomelic dysplasia. a At age 2 days, a lateral radiograph shows anterior bowing of the tibia and fibula and femur (which was bilateral). The mid left tibia demonstrates a broad Bowdler spur and opposite it, a deep skin dimple (which was also bilateral). b An anteroposterior radiograph in the same patient at age 20 years shows the spur as mid-distal tibia medial, with the deep skin dimple, again, opposite it

\section{Compliance with Ethical Standards}

Conflicts of interest None

\section{References}

1. Oestreich AE, Bofinger MK (1989) Prominent transverse (Bowdler) bone spurs as a diagnostic clue in a case of neonatal hypophosphatasia without metaphyseal irregularity. Pediatr Radiol 19:341-342

2. Kozlowski K, Sutcliffe J, Barylak A et al (1976) Hypophosphatasia. Review of 24 cases. Pediatr Radiol 5:103-117 